\title{
Spontaneous pneumothorax: stop chest tube as first-line therapy
}

\author{
Jean-Marie Tschopp ${ }^{1}$ and Charles-Hugo Marquette ${ }^{2}$
}

Affiliations: ${ }^{1}$ Centre Valaisan de Pneumologie, Montana, Switzerland. ${ }^{2}$ Université Côte d'Azur, CHU de Nice, FHU Oncoage, Service de Pneumologie, Nice, France.

Correspondence: Jean-Marie Tschopp, 20 rue du Poiet, 3963 Montana, Switzerland.

E-mail: jeanmarietschoppdoutlook.com

@ERSpublications

In this issue of the ERJ, a randomised study shows that simple aspiration can be very successful in both PSP and SSP http://ow.ly/8h7u309Wmji

Cite this article as: Tschopp J-M, Marquette C-H. Spontaneous pneumothorax: stop chest tube as first-line therapy. Eur Respir J 2017; 49: 1700306 [https://doi.org/10.1183/13993003.00306-2017].

Spontaneous pneumothorax is traditionally divided between primary spontaneous pneumothorax (PSP) and secondary spontaneous pneumothorax (SSP) when there is some underlying lung disease. For decades management of spontaneous pneumothorax has remained highly debatable despite different published guidelines [1-3], many of which contradict each other. Our task force, comprising a multidisciplinary panel of pulmonologists, thoracic surgeons and epidemiologists, recently published a consensus statement [4] on PSP to highlight new findings on the clinical approach, pathophysiology and management strategies of this disease. Pneumothorax remains an under-researched area. The epidemiology of PSP is still poorly documented regarding risk factors or rates of recurrence of PSP. Although smoking remains the principal and well-established risk factor [5], advice for quitting smoking [6] should be routinely given. This disease affects young patients in good health. They are therefore an ideal target population for receiving preventive advice. The pathophysiology of PSP is better understood because of many recent findings. The old concept [7] of PSP because of a localised rupture of a bleb or a bulla is obsolete and has been questioned by many recent studies. We now have robust evidence that the occurrence of PSP is mainly the result of a diffuse histopathological change of the lung parenchyma under the visceral pleura known as emphysema-like changes $[8,9]$. There is also a diffuse decrease in the lung density measured by computed tomography (CT) [10] and diffuse increased porosity [11] at the periphery of both lungs. These recent findings explain why a localised surgical approach is less effective than a diffuse pleurodesis, whatever the method of pleurodesis used $[12,13,14]$. Most patients with PSP have no or minimal symptoms, and the entire panel of this European task force [4] agreed that the clinical evaluation of patients with PSP should be more symptom driven and not based only on the measurement of the size of pneumothorax on plain chest radiography or CT, which have little clinical value $[15,16]$. Tension pneumothorax is very rare [17]. Most patients with spontaneous pneumothorax commonly experience minimal or no symptoms.

In recent years, there has been a change in the management strategy of spontaneous pneumothorax leading to more use of a conservative approach $[1,3]$ based on the idea that air in the pleural cavity is well supported. This is not surprising. Chest physicians historically were familiar with inducing artificial pneumothorax in cases of tuberculosis and using the same apparatus for aspirating pneumothorax on an ambulatory basis. With the advent of the chest tube, the use of chest tube drainage (CTD) became widespread although such an approach required hospitalisation and was mainly practised by surgeons [18] and not by pulmonologists. 50 years ago, Stradling and Poole [19] had already recommended a conservative and outpatient treatment of pneumothorax. Later on, many randomised studies [20-25]

Received: Feb 122017 | Accepted: Feb 162017

Conflict of interest: None declared.

Copyright CERS 2017 
proved that simple needle aspiration significantly reduced hospital stay without a higher recurrence rate of pneumothorax, explaining the choice of needle aspiration as a first-line therapy recommended by some guidelines [1, 3]. However, all these well-controlled studies dealt with PSP, apart from the study by ANDRIVET et al. [23], which included eight SSP cases in their data.

In this issue of the European Respiratory Journal, Thelle et al. [26] have published a randomised study comparing needle aspiration and CTD in 127 patients with spontaneous pneumothorax. This study is interesting for many reasons. It was carried out by a multidisciplinary team that included pulmonologists, thoracic surgeons and public health scientists. It was performed in different hospitals and included a substantial number of SSP (48 SSP out of 127 cases). This study covered two pulmonary departments and one surgical department and was carried out by junior physicians and thus reflects normal clinical life in clinical practice. To our knowledge, it is the first randomised study with such an important number of patients with SSP. Hospital stay and the immediate success rate were significantly and respectively shorter and higher in the needle aspiration group than the CTD group. Interestingly, these two parameters remained significantly better when separately analysing the results in PSP and SSP. There were no complications after needle aspiration but 15 patients undergoing CTD presented some complications. These results are new and important for the clinician. They confirm the real benefit of simple needle aspiration in both PSP and SSP. They will contribute to modifying the guidelines recommendations in cases of SSP.

If confirmed by other studies, the first line of treatment in a first episode of spontaneous pneumothorax has definitely to be observation, or needle aspiration if some treatment has to be offered to the patient. Unless there really is some respiratory distress, one should definitely avoid chest tube insertion, which is not only painful for the patient, as shown by AYED et al. [24], but exposes him/her to a risk of potential complications. Contrary to PSP, patients with SSP are more at risk of complications from chest drainage because of their underlying lung disease and one ought to avoid exposing them to unnecessary immobilisation. One might argue that a lower rate of complications would have been recorded if the procedure were done by more experienced physicians and not by junior doctors on call. The rate of complications found in this study is the same as in other similar studies. This study describes the usual process for looking after patients with spontaneous pneumothorax; the reality is that in most hospitals, cases of pneumothorax are usually looked after by young doctors. It also shows that these young doctors had been well taught how to perform needle aspiration. That is not always the case in hospital practice [27]. Such a study will help stimulate more prospective and controlled studies on spontaneous pneumothorax, such as the current Australasian multidisciplinary study [28]. Too many publications on pneumothorax deal with retrospective studies carried out in the same department with biased recruitment of patients. We need to better define the best way of ambulatory management for a first episode of pneumothorax and make treatment of pneumothorax as cost-effective as possible. The use of an ambulatory Heimlich valve might be a new and promising approach, as recently shown $[29,30]$.

Spontaneous pneumothorax remains an area for further research. In the meantime, the study by TheLLE et al. [26] is an important one to improve the management of both primary and secondary pneumothorax more conservatively. Every clinician also ought to routinely provide more advice about smoking cessation to reduce the chance of recurrence in patients with a first episode of pneumothorax.

\section{References}

1 MacDuff A, Arnold A, Harvey J, et al. Management of spontaneous pneumothorax: British Thoracic Society pleural disease guideline 2010. Thorax 2010; 65: Suppl. 2, ii18-ii31.

2 Baumann MH, Strange C, Heffner JE, et al. Management of spontaneous pneumothorax: an American College of Chest Physicians Delphi consensus statement. Chest 2001; 119: 590-602.

3 De Leyn P, Lismonde M, Ninane V, et al. Belgian Society of Pneumology. Guidelines on the management of spontaneous pneumothorax. Acta Chir Belg 2005; 105: 265-267.

4 Tschopp JM, Bintcliffe O, Astoul P, et al. ERS task force statement: diagnosis and treatment of primary spontaneous pneumothorax. Eur Respir J 2015; 46: 321-335.

5 Bense L, Eklund G, Wiman LG. Smoking and the increased risk of contracting spontaneous pneumothorax. Chest 1987; 92: 1009-1012.

6 Smit HJ, Chatrou M, Postmus PE. The impact of spontaneous pneumothorax, and its treatment, on the smoking behaviour of young adult smokers. Respir Med 1998; 92: 1132-1136.

7 Vanderschueren RG. Le talcage pleural dans le pneumothorax spontané [Pleural talcage in spontaneous pneumothorax]. Poumon Coeur 1981; 37: 273-276.

8 Ohata M, Suzuki H. Pathogenesis of spontaneous pneumothorax. With special reference to the ultrastructure of emphysematous bullae. Chest 1980; 77: 771-776.

$9 \quad$ Noppen F, Schramel F. Pneumothorax. Eur Respir Monogr 2002; 22: 279-296.

10 Smit HJ, Golding RP, Schramel FM, et al. Lung density measurements in spontaneous pneumothorax demonstrate air trapping. Chest 2004; 125: 2083-2090.

11 Noppen M, Dekeukeleire T, Hanon S, et al. Fluorescein-enhanced autofluorescence thoracoscopy in patients with primary spontaneous pneumothorax and normal subjects. Am J Respir Crit Care Med 2006; 174: 26-30.

12 Nakanishi K. Long-term effect of a thoracoscopic stapled bullectomy alone for preventing the recurrence of primary spontaneous pneumothorax. Surg Today 2009; 39: 553-557. 
13 Horio $\mathrm{H}$, Nomori $\mathrm{H}$, Kobayashi $\mathrm{R}$, et al. Impact of additional pleurodesis in video-assisted thoracoscopic bullectomy for primary spontaneous pneumothorax. Surg Endosc 2002; 16: 630-634.

14 Loubani M, Lynch V. Video assisted thoracoscopic bullectomy and acromycin pleurodesis: an effective treatment for spontaneous pneumothorax. Respir Med 2000; 94: 888-890.

15 Kelly AM, Druda D. Comparison of size classification of primary spontaneous pneumothorax by three international guidelines: a case for international consensus? Respir Med 2008; 102: 1830-1832.

16 Hoi K, Turchin B, Kelly AM. How accurate is the Light index for estimating pneumothorax size? Australas Radiol 2007; 34: 196-198.

17 Noppen M, De Keukeleire T. Pneumothorax. Respiration 2008; 76: 121-127.

18 Lindskog GE, Halasz NA. Spontaneous pneumothorax: a consideration of pathogenesis and management with review of seventy-two hospitalized cases. Arch Surg 1957; 75: 693-698.

19 Stradling P, Poole G. Conservative management of spontaneous pneumothorax. Thorax 1966; 21: 145-149.

20 Korczyński P, Górska K, Nasiłowski J, et al. Comparison of small bore catheter aspiration and chest tube drainage in the management of spontaneous pneumothorax. Adv Exp Med Biol 2015; 866: 15-23.

21 Noppen M, Alexander P, Driesen P, et al. Manual aspiration versus chest tube drainage in first episodes of primary spontaneous pneumothorax: a multicenter, prospective, randomized pilot study. Am J Respir Crit Care Med 2002; 165: 1240-1244.

22 Harvey J, Prescott RJ. Simple aspiration versus intercostal tube drainage for spontaneous pneumothorax in patients with normal lungs. British Thoracic Society Research Committee. BMJ 1994; 309: 1338-1339.

23 Andrivet P, Djedaini K, Teboul JL, et al. Spontaneous pneumothorax. Comparison of thoracic drainage vs immediate or delayed needle aspiration. Chest 1995; 108: 335-339.

24 Ayed AK, Chandrasekaran C, Sukumar M. Aspiration versus tube drainage in primary spontaneous pneumothorax: a randomised study. Eur Respir J 2006; 27: 477-482.

25 Parlak M, Uil SM, van den Berg JW. A prospective, randomised trial of pneumothorax therapy: manual aspiration versus conventional chest tube drainage. Respir Med 2012; 106: 1600-1605.

26 Thelle A, Gjerdevik M, SueChu M, et al. Randomised comparison of needle aspiration and chest tube drainage in spontaneous pneumothorax. Eur Respir J 2017; 49: 1601296.

27 Packham S, Jaiswal P. Spontaneous pneumothorax: use of aspiration and outcomes of management by respiratory and general physicians. Postgrad Med J 2003; 79: 345-347.

28 Brown SG, Ball EL, Perrin K, et al. Study protocol for a randomised controlled trial of invasive versus conservative management of primary spontaneous pneumothorax. BMJ Open 2016; 6: e011826.

29 Marquette $\mathrm{CH}$, Marx A, Leroy S, et al. Simplified stepwise management of primary spontaneous pneumothorax: a pilot study. Eur Respir J 2006; 27: 470-476.

30 Massongo M, Leroy S, Scherpereel A, et al. Outpatient management of primary spontaneous pneumothorax: a prospective study. Eur Respir J 2014; 43: 582-590. 